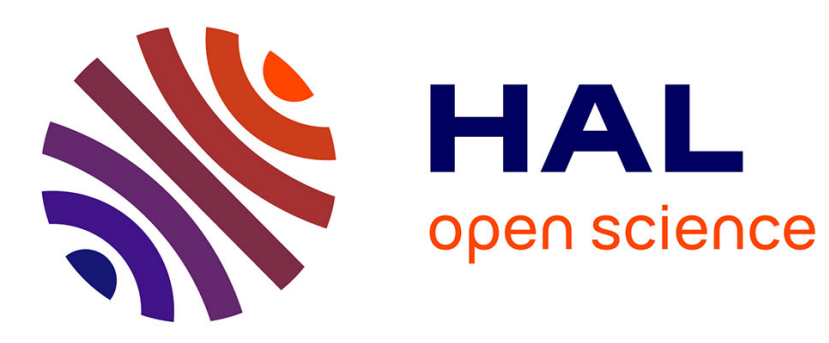

\title{
Assessing the effectiveness of drawing an autobiographical memory as a mood induction procedure in children
}

Catherine Monnier, Arielle Syssau, Nathalie Blanc, Claire Brechet

\section{- To cite this version:}

Catherine Monnier, Arielle Syssau, Nathalie Blanc, Claire Brechet. Assessing the effectiveness of drawing an autobiographical memory as a mood induction procedure in children. 2015. halshs01247490

\section{HAL Id: halshs-01247490 \\ https://shs.hal.science/halshs-01247490}

Preprint submitted on 4 Jan 2016

HAL is a multi-disciplinary open access archive for the deposit and dissemination of scientific research documents, whether they are published or not. The documents may come from teaching and research institutions in France or abroad, or from public or private research centers.
L'archive ouverte pluridisciplinaire HAL, est destinée au dépôt et à la diffusion de documents scientifiques de niveau recherche, publiés ou non, émanant des établissements d'enseignement et de recherche français ou étrangers, des laboratoires publics ou privés. 


\section{Assessing the effectiveness of drawing an autobiographical memory as a mood induction procedure in children}

Authors: Catherine Monnier, Arielle Syssau, Nathalie Blanc, and Claire Brechet

Addresses of the authors:

Catherine Monnier, Dr.: Laboratoire Epsylon, Université Paul-Valéry Montpellier, Route de Mende, 34199 Montpellier Cedex 5, France, e-mail : catherine.monnier@univ-montp3.fr Arielle Syssau, Dr.: Laboratoire Epsylon, Université Paul-Valéry Montpellier, Route de Mende, 34199 Montpellier Cedex 5, France, e-mail : arielle.syssau@univ-montp3.fr Nathalie Blanc, Pr.: Laboratoire Epsylon, Université Paul-Valéry Montpellier, Route de Mende, 34199 Montpellier Cedex 5, France, e-mail : nathalie.blanc@univ-montp3.fr Claire Brechet, Dr.: Laboratoire Epsylon, Université Paul-Valéry Montpellier, Route de Mende, 34199 Montpellier Cedex 5, France, e-mail : claire.brechet@univ-montp3.fr

Short title: drawing an autobiographical memory as a mood induction procedure in children

$\underline{\text { Address for correspondence: }}$

Catherine Monnier

Laboratoire Epsylon, Université Paul-Valéry Montpellier, Route de Mende, 34199

Montpellier Cedex 5, France

e-mail: catherine.monnier@univ-montp3.fr 


\begin{abstract}
The objective of our study was to examine the effectiveness of a new version of the autobiographical recall procedure (i.e., drawing a happy personal event) in eliciting a positive mood in 6-, 8- and 10-year-old children and to compare the drawing condition to the more classical telling condition. The mood of children was assessed before and after induction using the Self-Assessment Manikin (SAM, Lang, 1980) and across the two emotional dimensions of valence and arousal. The results showed that the drawing condition was as effective as the telling condition for inducing a positive mood. Furthermore, in the drawing condition, children reported feeling calmer than in the telling condition, suggesting that drawing was more likely to help children regulate their emotional state. The drawing procedure could be used in future research aiming to induce positive moods in school-aged children, to help further investigate the relationship between cognition and emotion.
\end{abstract}

Keywords: Mood induction, autobiographical memories, children, drawing 


\section{Introduction}

The relationship between emotion and cognition is garnering increasing attention. For instance, many researchers are currently investigating the effect of mood on children's cognitive performance. To do so, some researchers make use of children’s naturally occurring moods (e.g., Visu-Petra, Ţincaş, Cheie, \& Benga, 2010; Wagner, Müller, Helmreich, Huss, \& Tadic, 2015) whereas others attempt to artificially induce moods (e.g., Fartoukh, Chanquoy, \& Piolat, 2014; Rader \& Hughes, 2005). Brenner (2000) reviewed seven different types of procedures which can be used to induce mood in children: 1) self-generated imagery, 2) experimenter behavior, 3) experimental instructions, 4) emotional stories, 5) evocative videotapes, 6) success-failure or false feedback, and 7) gift-prizes. In the self-generated imagery procedure, children are asked to retrieve and dwell upon a personal event or situation in which they had experienced a specified mood. In the experimenter behavior procedure, children's mood is manipulated through positive reinforcement or punishing. The experimental instructions procedure consists in manipulating the information given to the children at the onset of the experiment (for instance, anxiety can be induced by warning children that their responses to the task will be evaluated). The emotional stories and the evocative videotapes procedures are used to induce a mood by reading emotional stories or showing emotional programs to the children. Finally, in the two last procedures, children are given positive or negative feedback, or receive prizes after a laboratory task (e.g. a toy, a book, markers).

Self-generated imagery is the most commonly used procedure with children. Brenner (2000) reported that it was used in sixty-four percent of the studies he reviewed, with few methodological variations. In this procedure, children are asked to evoke a vivid image of an emotional personal experience and then to either mentally ponder or verbally recount this event. The verbal recount version of the self-generated imagery procedure is also called 
autobiographical recall (Jallais \& Gilet, 2010; Levine, Burgess, \& Laney, 2008; Schaefer \& Philippot, 2005). Autobiographical recall is considered one of the most effective induction techniques and seems particularly efficient for inducing positive moods (Strack, Schwarz, \& Gschneidinger, 1985). Furthermore, autobiographical recall has been successfully used to induce a wide range of specific positive or negative moods such as happiness, serenity, sadness or anger (e.g., Jallais \& Gilet, 2010; Nasby \& Yando, 1982).

Nevertheless, despite its proven reliability as a reliable induction procedure with children, autobiographical recall suffers from several drawbacks. First, recounting an autobiographical memory requires having the corresponding language skills, which may be quite challenging for young children or for children with linguistic impairment. Second, it can be difficult for children to verbally confide in an adult experimenter about personal events. Third, when using this technique, researchers need to test children individually. To avoid these limitations, we proposed an alternative procedure: Instead of recounting an autobiographical memory, children could be asked to draw it. Indeed, drawing is considered a public instrument of representation and a powerful nonverbal tool with which children can express their mood (Brooks, 2005; Freeman, 1980; Malchiodi, 1998). Furthermore, drawing is a pleasant and familiar activity for children, and it can help them disclose their thoughts on personal topics (Kirova, 2006).

The objective of our study was to broaden the range of mood induction procedures available for children. More precisely, we aimed to assess the effectiveness of a specific version of the autobiographical recall procedure which has never been used and which consists in asking children to evoke and draw an emotional personal experience (i.e., drawing condition). We compared this drawing recall condition to a condition which has already shown to be reliable in children and which consists in asking children to evoke and tell an emotional personal experience (i.e., telling condition). We examined the effects of these two 
conditions of the autobiographical recall procedure (i.e., drawing versus telling) on eliciting positive and neutral emotional states in children aged 6 to 10 years. For ethical considerations, and to preserve the emotional balance of the children in our sample, we did not induce negative moods; indeed, children's ability to reverse negative mood states may not be as developed as adults' (Barden, Garber, Leiman, Ford, \& Masters, 1985). To assess the mood of the participants, we used the Self-Assessment Manikin (SAM, Lang, 1980), a self-report measure. We examined both dimensions of mood: valence (positive versus negative) and arousal (level of activation ranging from calm/relaxed to excited).

\section{Method}

\section{Participants}

A total of 597 French children participated in the study: one hundred ninety-eight 6-yearold children (89 girls; mean age $=6$ years and 7 months; $\min =6$ years and 2 months; $\max =7$ years and 2 months; SD = 3 months), one hundred ninety-six 8-year-old children (95 girls; mean age $=8$ years and 7 months; $\min =8$ years and 1 month; max $=9$ years and 4 months; $\mathrm{SD}=4$ months $)$ and two hundred and three 10 -year-old children (100 girls; mean age $=10$ years and 8 months; $\min =10$ years and 2 months; $\max =11$ years and 4 months; $\mathrm{SD}=4$ months). None were academically advanced or delayed. The children were recruited from public schools located in or around the city of Montpellier in the south of France. This area features a broad range of socioeconomic strata. Parental informed consent was obtained for all the children who participated voluntarily in the study. The children in each age group were randomly assigned to one of four experimental conditions (positive mood induction/telling; positive mood induction/drawing; neutral mood induction/telling; neutral mood induction/drawing). 


\section{Materials}

In order to evaluate the children's emotional state before and after mood induction, we used a paper version of the Self-Assessment Manikin (SAM, Lang, 1980). Mood valence was assessed using the 9-point SAM scale, which ranges from a smiling, happy figure to a frowning, unhappy figure. Mood arousal was assessed using the 9-point SAM scale which ranges from an excited, wide-eyed figure to a relaxed, sleepy figure. Because SAM is a nonverbal, pictographic self-report measure, it can easily be implemented with children and has been successfully used with children aged 6 to 12 years (e.g., McManis, Bradley, Berg, Cuthbert, \& Lang, 2001; Von Leopoldt et al., 2007). Furthermore, from the age of 6, children are able to discriminate between, and separately assess, the valence and arousal dimensions of mood (Leonhardt, Könen, Dirk, \& Schmiedek, 2015). Figure 1 shows the SAM used to assess mood valence and mood arousal. For the drawing condition, the participants were also given individual sheets of white A4 paper and a regular grey pencil.

\section{Procedure}

The experiment was conducted individually in an empty and quiet classroom. It lasted for 10 minutes on average and comprised 3 stages: first, we assessed the child's emotional state before mood induction; second, we induced the mood; third and last, we assessed the child's emotional state after mood induction.

Assessment of the emotional state before induction. The valence and arousal SAM scales were successively presented to the child. The instructions given to the child on how the SAM scales were to be used had been adapted from Lang, Bradley, and Cuthbert (2008). After listening to the instructions, the child was invited to rate his/her emotional state from happy (9) to unhappy (1) and the associated level of arousal from excited (9) to calm (1) by pointing to the corresponding answer on the 9-point SAM scales. 
Mood induction. The emotional states were manipulated using a between-participant design with a two-level valence (positive, neutral).

Positive mood induction. The experimenter first instructed the child to mentally evoke a positive episode of his/her life. The child was invited to think about all the details of this episode. The instructions were adapted from Schaefer and Philippot (2005):

"I would like you to remember a life event that made you very, very happy. If you feel like it, you can close your eyes and try to picture it in your head. Think about what happened, with whom you were, when and where it took place. Now try to think about this moment very hard. When you feel you remember clearly this moment that made you very, very happy, tell me.”

The experimenter allowed the child to reminisce for 30 seconds maximum. The child was then instructed to draw or tell the positive event.

"Now I would like you to draw/tell this moment that made you very, very happy"

The recollection stage lasted for 1 to 10 minutes. When the child drew/told for less than 1 minute, the child was prodded:

"Try to tell/draw what happened, with whom you were, when and where it took place". Neutral mood induction. The experimenter first instructed the child to mentally evoke what his/her classroom looked like. The child was asked to think about all the details of that room. "I would like you to remember what your classroom looks like. If you feel like it, you can close your eyes and try to picture where the desks are located, what ornaments are on the walls, where the windows, the door and the board are located, and where the books go. Now, I would like you to think about your classroom very hard. When you feel you remember your classroom clearly, tell me."

The experimenter allowed the child to reminisce for 30 seconds maximum. The child was then instructed to draw or to describe his/her classroom. 
"Now I would like you to draw/describe your classroom"

The recollection stage lasted for 1 to 10 minutes. When the child drew/told for less than 1 minute, the child was reminded:

"Try to draw/tell where the desks are located, what ornaments are on the walls, where the windows, the door and the board are located, and where the books go." Assessment of the emotional state after induction. The valence and arousal SAM scales were presented again to the child, who was invited to indicate how he/she felt while drawing or telling his/her memory or classroom from happy (9) to unhappy (1) and the associated level of arousal from excited (9) to calm (1).

\section{Results}

Valence mood ratings ranged from 1 (unhappy) to 9 (happy). Table 1 shows the means and standard deviations of the mood ratings of children in each age group and in each experimental condition at both mood assessment times (i.e., Time 1: before the mood induction procedure, and Time 2: after the mood induction procedure).

(Table 1 about here)

A mixed five-factor ANOVA was carried out with age (6-, 8- or 10-year-olds), gender (girl or boy), mood group (positive or neutral mood) and recall condition (drawing or telling) as between-participants factors, and mood assessment time (Time 1 or Time 2) as the withinparticipants factor. Gender had a significant effect on the mood valence ratings, $F(1,573)=$ 5.15, $p<.05, \eta_{p}^{2}=.009, M S E=2.83$, indicating that girls $(M=7.84, S D=1.48)$ obtained higher scores than boys $(M=7.62, S D=1.53)$. The effect of age was significant, $F(2,573)=$ $17.51, p<.001, \eta_{p}^{2}=.06, M S E=2.83$. Post hoc analysis (Scheffé test) revealed superior 
mood valence ratings at age $6(M=8.08, S D=1.53)$ than at age $8(M=7.74, S D=1.37)$ and at age 8 than at age $10(M=7.37, S D=1.53), p s<.05$. The ANOVA also revealed an effect of mood group, $F(1,573)=14.24, p<.001, \eta_{p}^{2}=.02, M S E=2.83$, and a significant interaction between mood group and mood assessment time, $F(1,573)=25.50, p<.001, \eta_{p}^{2}=$ $.04, M S E=1.43$. Post hoc analysis (Scheffé test) revealed that the mood groups did not differ significantly in mood valence ratings at Time 1 (before mood induction, $M=7.70, S D=1.54$ for the neutral mood group and $M=7.71, S D=1.44$ for the positive mood group), $p=.99$. In contrast, the mood groups differed significantly at Time 2 (after mood induction), $p<.0001$. The positive mood group $(M=8.12, S D=1.22)$ reported feeling happier than the neutral mood group $(M=7.39, S D=1.70)$ after mood induction. Other main effects and interactions were not significant.

Arousal mood ratings ranged from 1 (calm) to 9 (excited). Table 1 lists descriptive statistics for the mood arousal ratings of the three age groups and for each experimental condition at both mood assessment time (i.e., Time 1: before the mood induction procedure, and Time 2: after the mood induction procedure).

These data were subjected to a five-factor ANOVA with age (6-, 8- or 10-year-olds), gender (girl or boy), mood group (positive or neutral mood) and recall condition (drawing or telling) as between-participants factors, and mood assessment time (Time 1 or Time 2) as the within-participants factor. This analysis revealed a main effect of mood group, $F(1,573)=$ 8.69, $p<.01, \eta^{2}=.01, M S E=10.09$, which was qualified by a mood group by mood assessment time interaction, $F(1,573)=17.80, p<.0001, \eta_{p}^{2}=.03, M S E=4.19$. Further post hoc analysis (Scheffé test) showed that the mood groups did not differ significantly in mood arousal ratings at Time 1 (before mood induction, $M=4.74, S D=2.57$ for the neutral mood group and $M=4.78, S D=2.58$ for the positive mood group), $p=.99$. In contrast, at Time 2 (after mood induction), the positive mood group $(M=5.09, S D=2.91$ ) reported feeling more 
excited than the neutral mood group $(M=4.04, S D=2.63), p<.001$. There also was a significant interaction of Recall Condition X Mood Assessment Time, $F(1,573)=11.96, p$ $<.001, \eta_{p}^{2}=.02, M S E=4.19$. A post hoc analysis (Scheffé test) revealed that children clearly differed in mood arousal ratings between Time 1 and 2 when they had to draw the memory ( $M$ $=4.89, S D=2.59$ at Time 1 and $M=4.28, S D=2.72$ at Time 2$), p<.01$ but not when they had to tell it $(M=4.63, S D=2.56$ at Time 1 and $M=4.84, S D=2.90$ at Time 2$), p=.73$. To sum up, children reported feeling calmer after drawing than before doing so. Other main effects and interactions were not significant.

\section{Discussion}

The objective of our study was to examine the effectiveness of a new version of the autobiographical recall procedure (i.e., drawing a happy personal event) in eliciting a positive mood in children and to compare this drawing recall condition to the more classical telling recall condition. The mood of children was assessed on the two emotional dimensions of valence and arousal, using the Self-Assessment Manikin (SAM, Lang, 1980).

Regarding valence ratings, our findings clearly indicated that children in the positive mood group reported feeling happier than children in the neutral mood group. This was the case regardless of the children's age and the type of autobiographical recall procedure used (i.e., drawing and telling). Our results also showed that the valence ratings of girls were higher than those of boys, and that children's valence ratings decreased with age. These findings are consistent with previous ones (e.g., McManis et al., 2001; Vasa, Carlino, London, \& Min, 2006; Von Leupoldt et al., 2007).

Regarding arousal ratings, our findings revealed that children in the positive mood group reported feeling calmer than children in the neutral mood group, regardless of their age and of the autobiographical recall condition. This result corresponds to those of previous 
studies conducted not only with adults (Jallais \& Gilet, 2010), but also with children (Von Leupold et al., 2007). Furthermore, we highlighted an important difference between the two recall conditions. Children who were subjected to the drawing task - regardless of the target mood (neutral or positive) - reported feeling calmer after the induction than before it. This benefit was not observed with children in the more classical telling recall condition.

Drake and Winner (2013) already showed that drawing could be used with children as a mood regulation technique, with a specific effect on valence. In fact, our results extend those obtained by Drake and Winner (2013): The children in our study reported a calmer emotional state after drawing, and we therefore suggest that arousal could be improved with the use of a drawing procedure.

The main contribution of this study therefore lies in offering evidence that drawing a happy personal event is an efficient procedure to elicit a positive mood in 6-, 8- and 10 yearold children. A drawing procedure such as the one used in the present study is particularly suitable for children for at least three reasons. First, because it is a nonverbal tool, it can be used with young children or with children with language impairment. Second, the use of a drawing condition may allow children to express their emotional autobiographical memories more overtly, thereby allowing a less intrusive procedure than a telling condition. Third, this drawing condition allows researchers to test children collectively.

We chose to focus the present study on the induction of a positive mood. This choice was motivated by ethical considerations, and also by the potential transferability of our results to the field of education, where the importance of positive emotions has already been demonstrated (Pekrun, Goetz, Titz, \& Perry, 2002). Indeed, positive emotional states have been shown to improve flexibility, problem solving, verbal fluency and creative thinking in adults (for a review, see Ashby, Isen, \& Turken, 1999). However, studies interested in this 
topic in children remain scarce. Using the drawing procedure to induce a positive mood could allow researchers to collect more empirical evidence and to complement existing models.

Finally, we opted for a dimensional approach to our assessment of the children's emotional state (valence and arousal). To further examine the effects of a positive mood on cognitive processing as proposed by Fredrickson (1998), it would be interesting to use a categorical approach of positive emotions to distinguish between discrete emotions such as amusement, contentment, happiness and serenity. Thus, we recommend that future works examine the effectiveness of the autobiographical recall drawing procedure to elicit a wide range of positive discrete emotions in children.

\section{References}

Ashby, F. G., Isen, A. M., \& Turken, A. U. (1999). A neuropsychological theory of positive affect and its influence on cognition. Psychological Review, 106(3), 529550.doi:10.1037/0033-295X.106.3.529

Barden, R. C., Garber, J., Leiman, B., Ford, M. E., \& Masters, J. C. (1985). Factors governing the effective remediation of negative affect and its cognitive and behavioral consequences. Journal of Personality and Social Psychology, 49(4), 1040-1053. doi:10.1037/0022-3514.49.4.1040

Brenner, E. (2000). Mood induction in children: Methodological issues and clinical implications. Review of General Psychology, 4(3), 264-283. doi:10.1037/10892680.4.3.264

Brooks, M. (2005). Drawing as a unique mental development tool for young children: Interpersonal and intrapersonal dialogues. Contemporary Issues in Early Childhood, 6, 80-91. 
Drake, J. E., \& Winner, E. (2013). How children use drawing to regulate their emotions. Cognition and Emotion, 27(3), 512-520. doi:10.1080/02699931.2012.720567

Fartoukh, M., Chanquoy, L., \& Piolat, A. (2014). Mood induction in children: Effect of the affective valence of a text on phonological working memory. Advances in Cognitive Psychology, 10(3), 113-118. doi:10.5709/acp-0162-z

Fredrickson, B. L. (1998). What good are positive emotions? Review of General Psychology, 2(3), 300-319. doi:10.1037/1089-2680.2.3.300

Freeman, N. H. (1980). Strategies of representation in young children: Analysis of spatial skills and drawing processes. London: Academic Press.

Jallais, C., \& Gilet, A. (2010). Inducing changes in arousal and valence: Comparison of two mood induction procedures. Behavior Research \& Methods, 42(1), 318-325. doi:10.3758/BRM.42.1.318

Kirova, A. (2006). A game-playing approach to interviewing children about loneliness: Negotiating meaning, distributing power, and establishing trust. Alberta Journal of Educational Research, 52, 127-147.

Lang, P. J. (1980). Behavioral treatment and bio-behavioral assessment: Computer applications. In J. B. Sidowski, J. H. Johnson, \& T. A.William (Eds.), Technology in mental health care delivery systems (pp. 119-137). Norwood, NJ: Ablex.

Lang, P. J., Bradley, M. M., \& Cuthbert, B. N. (2008). International affective picture system (IAPS): Affective ratings of pictures and instruction manual (Technical Report A-8). Gainesville: University of Florida, NIMH Center for Research in Psychophysiology. Leonhardt, A., Könen, T., Dirk, J., \& Schmiedek, F. (2015). How differentiated do children experience affect? An investigation of the within- and between-person structure of children’s affect. Psychological Assessment, doi:10.1037/pas0000195 
Levine, L. J., Burgess, S. L., \& Laney, C. (2008). Effects of discrete emotions on young children's suggestibility. Developmental Psychology, 44(3), 681-694. doi:10.1037/00121649.44.3.681

McManis, M. H., Bradley, M. M., Berg, W. K., Cuthbert, B. N., \& Lang, P. J. (2001). Emotional reactions in children: Verbal, physiological, and behavioral responses to affective pictures. Psychophysiology, 38(2), 222-231. doi:10.1017/S0048577201991140

Malchiodi, C. A. (1998). Understanding children's drawings. New York: Guilford Press. Nasby, W., \& Yando, R. (1982). Selective encoding and retrieval of affectively valent information: Two cognitive consequences of children's mood states. Journal of Personality and Social Psychology, 43(6), 1244-1253. doi:10.1037/0022-3514.43.6.1244

Pekrun, R., Goetz, T., Titz, W., \& Perry, R. P. (2002). Positive emotions in education. In E. Frydenberg, E. Frydenberg (Eds.), Beyond coping: Meeting goals, visions, and challenges (pp. 149-173). New York, NY, US: Oxford University Press.

Rader, N., \& Hughes, E. (2005). The influence of affective state on the performance of a block design task in 6- and 7-year-old children. Cognition and Emotion, 19(1), 143-150. doi:10.1080/02699930441000049

Schaefer, A., \& Philippot, P. (2005). Selective effects of emotion on the phenomenal characteristics of autobiographical memories. Memory, 13(2), 148160.doi:10.1080/09658210344000648

Strack, F., Schwarz, N., \& Gschneidinger, E. (1985). Happiness and reminiscing: The role of time perspective, affect, and mode of thinking. Journal of Personality and Social Psychology, 49(6), 1460-1469. doi:10.1037/0022-3514.49.6.1460

Vasa, R. A., Carlino, A. R., London, K., \& Min, C. (2006). Valence ratings of emotional and non-emotional words in children. Personality and Individual Differences, 41(6), 11691180. doi:10.1016/j.paid.2006.03.025 
Visu-Petra, L., Ţincaş, I., Cheie, L., \&Benga, O. (2010). Anxiety and visual-spatial memory updating in young children: An investigation using emotional facial expressions. Cognition and Emotion, 24(2), 223-240. doi:10.1080/02699930903387546

Von Leupoldt, A., Rohde, J., Beregova, A., Thordsen-Sörensen, I., Nieden, J. Z., \& Dahme, B. (2007). Films for eliciting emotional states in children. Behavior Research \& Methods, 39(3), 606- 609.

Wagner, S., Müller, C., Helmreich, I., Huss, M., \& Tadić, A. (2015). A meta-analysis of cognitive functions in children and adolescents with major depressive disorder. European Child \& Adolescent Psychiatry, 24(1), 5-19. doi:10.1007/s00787-014-0559-2 
Table 1.

Mean valence and mean arousal mood ratings (and standard deviations) for each age group and each experimental condition at both assessment times.

\begin{tabular}{|c|c|c|c|c|c|c|c|c|}
\hline & \multicolumn{4}{|c|}{ Drawing condition } & \multicolumn{4}{|c|}{ Telling condition } \\
\hline & \multicolumn{2}{|c|}{ Positive mood } & \multicolumn{2}{|c|}{ Neutral mood } & \multicolumn{2}{|c|}{ Positive mood } & \multicolumn{2}{|c|}{ Neutral mood } \\
\hline & Time 1 & Time 2 & Time 1 & Time 2 & Time 1 & Time 2 & Time 1 & Time 2 \\
\hline & \multicolumn{8}{|c|}{ Valence mood ratings } \\
\hline 6-year-olds & $7.9(1.7)$ & $8.3(1.0)$ & $8.4(1.3)$ & $7.7(1.9)$ & $8.1(1.5)$ & $8.6(0.8)$ & $7.8(1.9)$ & $7.8(1.7)$ \\
\hline 8-year-olds & $7.7(1.4)$ & $8.1(1.3)$ & $7.9(1.4)$ & $7.4(1.6)$ & $7.8(1.2)$ & $8.2(1.2)$ & $7.6(1.2)$ & $7.4(1.5)$ \\
\hline \multirow[t]{2}{*}{ 10-year-olds } & $7.3(1.4)$ & $7.6(1.5)$ & $7.2(1.6)$ & $7.2(1.6)$ & $7.5(1.4)$ & $8.0(1.3)$ & $7.3(1.5)$ & $6.9(1.8)$ \\
\hline & \multicolumn{8}{|c|}{ Arousal mood ratings } \\
\hline 6-year-olds & $4.9(2.8)$ & $4.9(3.0)$ & $4.2(3.0)$ & $3.5(2.7)$ & $4.3(2.9)$ & $5.4(3.3)$ & $4.5(2.9)$ & $3.9(2.8)$ \\
\hline 8-year-olds & $4.8(2.8)$ & $5.1(2.9)$ & $5.1(2.5)$ & $4.0(2.5)$ & $5.3(2.5)$ & $5.9(2.8)$ & $4.4(2.4)$ & $4.8(2.8)$ \\
\hline 10-year-olds & $4.8(2.2)$ & $4.2(2.6)$ & $5.5(1.9)$ & $4.0(2.4)$ & $4.6(2.1)$ & $5.3(2.7)$ & $4.8(2.4)$ & $3.9(2.6)$ \\
\hline
\end{tabular}

Note: Time 1 (before mood induction); Time 2 (after mood induction). 
Figure captions

Figure 1

SAM scales used to assess mood valence (top panel) and mood arousal (bottom panel). 

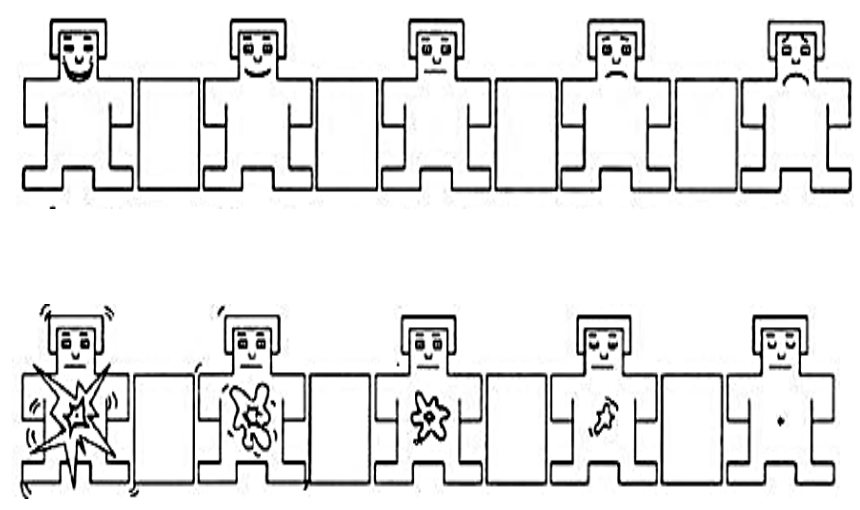

Figure 1 